\title{
Signal Intensity and Volume of Pituitary and Thyroid Glands in Preterm and Term Infants
}

\section{$\operatorname{AUTHOR}(S)$ :}

Otani, Sayo; Fushimi, Yasutaka; Iwanaga, Kogoro; Tomotaki, Seiichi; Yokota, Yusuke; Oshima, Sonoko; Sakurama, Azusa; ... Takita, Junko; Kawai, Masahiko; Togashi, Kaori

\section{CITATION:}

Otani, Sayo ...[et al]. Signal Intensity and Volume of Pituitary and Thyroid Glands in

Preterm and Term Infants. Journal of Magnetic Resonance Imaging 2021, 53(4): 1151-1161

\section{ISSUE DATE:}

2021-04

URL:

http://hdl.handle.net/2433/262574

\section{RIGHT:}

This is the peer reviewed version of the following article: [Signal Intensity and Volume of Pituitary and Thyroid Glands in Preterm and Term Infants, JMRI, 53(4), 1151-1161], which has been published in final form at

https://doi.org/10.1002/jmri.27395. This article may be used for non-commercial purposes in accordance with Wiley Terms and Conditions for Use of Self-Archived Versions.; The full-text file will be made open to the public on 16 October 2021 in accordance with publisher's 'Terms and Conditions for Self-Archiving: This is not the published version. Please cite only the published version. この論文は出版社版でありません。引用の際には出版社版をご確認ご利用ください。 
Signal Intensity and Volume of Pituitary and Thyroid Glands in Preterm and

\author{
Term Infants
}

\title{
ABSTRACT
}

BACKGROUND: Hypothalamic-pituitary-thyroid (HPT) maturation has not been extensively evaluated using neonatal MRI even though both structures are visualized on MRI.

HYPOTHESIS: That signal intensity and volume of pituitary and thyroid glands on MRI in neonates may be interrelated.

STUDY TYPE: Retrospective.

SUBJECTS: 102 participants.

FIELDSTRENGTH/SEQUENCE: 3.0 T, T1-weighted pointwise encoding time reduction with radial acquisition (PETRA).

ASSESSMENT: The volume of interest of anterior pituitary (AP), posterior pituitary (PP) and thyroid (T) on MRI were defined on T1-PETRA by two radiologists, and volumes of AP (AP_vol) and thyroid (T_vol) were calculated. Gestational age (GA), chronological age (CA), GA+CA, birth weight (BW), and thyroid function were 
recorded. Mean and maximum signal intensities of AP, PP, and T were normalized using signals from the pons and spinal cord as follows: AP/pons, $\mathrm{PP} /$ pons, and T/cord, respectively.

STATISTICAL TESTS: Correlations between signal intensity and volume measures and GA, CA, GA+CA, and BW were assessed using Pearson's correlation coefficient or Spearman's rank correlation coefficient. Thyroid function analysis and $\mathrm{T}_{\text {mean }} /$ cord, $\mathrm{T}_{\max } /$ cord, and T_vol were evaluated using the Steel-Dwass test.

Results: APmean/pons correlated positively with GA $(\rho=0.62, P<.001)$ and BW $(\rho=0.74$, $P<.001)$, and negatively with CA $(\rho=-0.86, P<.001)$ and GA+CA $(\rho=-0.46, P<.001)$. $\mathrm{PP}_{\text {mean }} /$ pons correlated positively with GA $(\rho=0.49, P<.001)$ and BW $(\rho=0.63, P<.001)$, and negatively with $\mathrm{CA}(\rho=-0.70, P<.001)$ and $\mathrm{GA}+\mathrm{CA}(\mathrm{r}=-0.38, P<.001)$. Tmean $/$ cord correlated positively with GA $(\rho=0.48, P<.001)$ and BW $(\rho=0.55, P<.001)$, and negatively with CA $(\rho=-0.59, P<.001)$ and $\mathrm{GA}+\mathrm{CA}(\rho=-0.22, P=.03)$. AP_vol correlated positively with GA $(\rho=0.68, P<.001)$ and BW $(\rho=0.73, P<.001)$, and negatively with CA $(\rho=-0.72, P<.001)$. T_vol correlated positively with GA $(\rho=0.50$, $P<.001)$ and BW $(\rho=0.61, P<.001)$, and negatively with CA $(\rho=-0.54, P<.001)$. $\mathrm{AP}_{\text {mean }} /$ pons correlated positively with $\mathrm{T}_{\text {mean }} / \operatorname{cord}(\rho=0.61, P<.001)$.

DATA CONCLUSION: Signal and volume of pituitary and thyroid glands correlated 
positively with GA and BW, and negatively with CA in neonates.

\section{Keywords}

Pituitary gland; Thyroid gland; Hypothalamic-pituitary-thyroid axis; Preterm infant; and PETRA.

\section{Running title}

Pituitary and Thyroid MR in Preterm and Term Infants

\section{Key points}

VOI analyses showed that the signal and volume of pituitary and thyroid glands correlated positively with gestational age and birth weight, and negatively with chronological age.

The signal of anterior pituitary signal correlated positively with the signal of thyroid gland.

\section{Abbreviations}

Hypothalamic-pituitary-thyroid, HPT; Anterior Pituitary, AP; Posterior Pituitary, PP; 
Thyroid, T; signal ratio of anterior pituitary /pons, AP/pons; signal ratio of posterior pituitary /pons, PP/pons; signal ratio of thyroid /cord, T/cord; volume of Anterior Pituitary, AP_vol; volume of thyroid, T_vol; gestational age, GA; chronological age, CA; birth weight, BW; L-thyroxine, L-T4; thyroid-stimulating hormone, TSH; Pointwise Encoding Time Reduction with Radial Acquisition, PETRA.

\section{Introduction}

Thyroid function is important for the fetus and neonate, as thyroid hormones play critical roles in the development and function of the central nervous system (1-3). Term infants undergo intensive maturation of the hypothalamic-pituitary-thyroid (HPT) axis at 35-40 gestational weeks, with increases in thyrotropin-releasing hormone and development of the hypothalamic-pituitary portal system $(4,5)$. Preterm infants receiving care in the neonatal intensive care unit after birth frequently exhibit hypothyroidism (1,6-8). Postulated causes of this hypothyroidism include immaturity of the HPT axis $(1,9)$.

MRI is often performed for preterm neonates with low birth weight (LBW) and postnatal growth retardation to assess the brain for abnormalities (10-12). The anterior lobe of the pituitary gland in the term infant is known to be hyperintense on T1- 
weighted imaging, which is attributed to a high amount of endoplasmic reticulum and high levels of protein synthetic activity (13-15). The signal from the anterior pituitary (AP) correlates negatively with chronological age (CA) (14-16), but relationships with the signal from the posterior pituitary (PP) have not been reported. The previous study focused on the estimation of pituitary volume by using the equation within the limited number of neonates such as 27 infants less than 1 year (17). In addition, volumetric studies of pituitary gland have not been performed well using neonatal MRI.

The thyroid gland is part of the HPT axis, but the intensity and volume of thyroid gland on MRI have not been evaluated in detail using neonatal MRI, although the volume has been evaluated on ultrasound by a simple estimation method $(6,18)$. We hypothesized that the intensity and volume of the pituitary and thyroid glands in neonates may be associated with each other. Thus the purpose of this study was to investigate whether intensity and volume of the pituitary gland and thyroid gland on MRI correlate with gestational age (GA), chronological age (CA), or birth weight (BW).

\section{Materials and Methods}

Subjects

This retrospective observation study was approved by the local institutional 
review board, and written informed consent was waived. Neonates who were admitted to neonatal intensive care unit and should be suspected or ruled out for central nervous system abnormalities were included in this study. We excluded the patients who have severe systemic abnormality or severe brain deformity. Total 76 preterm infants underwent MRI at term-equivalent age and 34 term infants underwent MRI when intracranial abnormalities were suspected between June 2015 and January 2019 at our hospital, but we only included 75 preterm infants and 27 term infants. One preterm infant and 7 term infants were excluded due to midline anomaly $(\mathrm{n}=2)$, achondroplasia $(n=2)$, large cyst $(n=2)$, Prader-Willi syndrome $(n=1)$, and severe motion artifacts $(n=1)$. As a result, a total of 102 neonates and infants ( 75 preterm and 27 term infants, 55 boys, 47 girls; GA, 164-290 days (23-41 weeks); CA, 6-134 days) without severe intracranial abnormalities were included in this study (Supplementary Material 1).

GA and CA were defined as the number of days between the first day of the mother's last menstrual period and the patient's date of birth, between the patient's date of birth and the date of MRI examination, respectively. The sum of the two ages $(\mathrm{GA}+\mathrm{CA})$ was also calculated for analysis. Patients were scanned around the termequivalent age, but the MRI scan date varied slightly with each patient. BW was also recorded. 
Image acquisition

Subjects underwent MRI on a 3 T scanner (MAGNETOM Skyra; Siemens Healthineers) with a 32-channel head coil. Whole-brain quiet 3D T1-weighted imaging was performed using a pointwise encoding time reduction with radial acquisition (PETRA) sequence with coverage from the upper thorax to the crown, so both the pituitary and thyroid glands were included in a single sequence (19). The central part of k-space was acquired with pointwise encoding after the first inversion pulse; whereas, the outer edge of $\mathrm{k}$-space was acquired using radial projections after the second and later inversion pulses (19). This 3D-T1-PETRA was designed to be equivalent to magnetization-prepared rapid gradient-echo sequence and the parameters was as follows: repetition time 1 (TR1)/TR2/TE, 4.0/2400/0.07 ms; inversion time 1 (TI1)/ TI2, 2000/800 ms; matrix, $256 \times 256$; field of view, $230 \times 230 \mathrm{~mm}^{2}$; flip angle, $6^{\circ}$; slice thickness, $0.9 \mathrm{~mm}$; 256 slices; bandwidth, $383 \mathrm{~Hz} / \mathrm{Px}$; and acquisition time, 3 min $29 \mathrm{~s}$.

Volume of interest analysis

Two radiologists (S.O. and K.P.W., 9 years and 8 years of neuroradiology experience, respectively) manually segmented the AP, PP, T, pons and cord using ITK- 
SNAP software (www.itksnap.org) independently, and segmented data was used as volumes of interest (VOIs) (Figure 1) (20). Final VOIs were confirmed by another radiologist (Y.F., 22 years of neuroradiology experience).

Mean and maximum intensities of the AP, PP and thyroid were calculated. Mean and max signal intensities of the AP, PP, and thyroid were normalized with reference to mean signals from the pons and cervical cord (thyroid level), as follows:

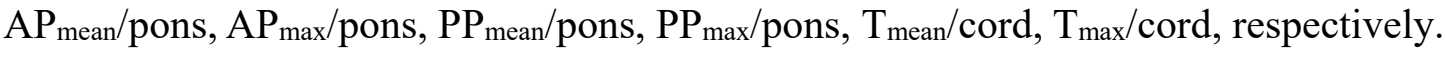
In addition, we calculated volume of the AP (AP_vol) and volume of the thyroid gland (T_vol) using ITK-SNAP.

Thyroid function analysis

We divided patients into 4 groups (Groups A-D) according to thyroid function analysis. If thyroid stimulating hormone $(\mathrm{TSH})>10 \mathrm{mIU} / \mathrm{L}$, hypothyroidism was diagnosed and treatment with L-thyroxine (L-T4) was started. In some patients, a certain amount of L-T4 had already been administered at the time of MRI in our hospital, and TSH values may have normalized. We assumed that patients diagnosed with hypothyroidism were the most pathologically severe cases, and we classified these as Group A. The remaining patients (without L-T4 treatment) were grouped based on 
TSH values measured on the day closest to the day of MRI: Group B had TSH $>5$

$\mu \mathrm{IU} / \mathrm{ml}$ and Group $\mathrm{C}$ had TSH $\leq 5 \mu \mathrm{IU} / \mathrm{ml}$. Healthy neonates without TSH

measurements were classified as Group D.

Statistical analysis

All data were analyzed using JMP Pro version 14.0 software (SAS Institute Inc.). Normal distribution was evaluated by the Shapiro-Wilk test. Continuous variables are presented as medians and interquartile, unless otherwise noted.

The relationship between pituitary signals (APmean/pons, $\mathrm{AP}_{\max } /$ pons, $\mathrm{PP}_{\text {mean }} /$ pons, and $\mathrm{PP}_{\max } /$ pons), thyroid signals ( $\mathrm{T}_{\text {mean }} /$ cord, $\mathrm{T}_{\max } /$ cord, $)$, and pituitary and thyroid volumes (AP_vol and T_vol, respectively) and ages (GA, CA, and GA+CA) and BW were assessed using Pearson's correlation coefficient (r) if both values were normally distributed and Spearman's rank correlation coefficient $(\rho)$ if one or both of the values was not normally distributed. Differences of $T_{\operatorname{mean}} /$ cord, $T_{\max } / c_{\text {cord }}$, and $T_{-}$vol were evaluated between patient groups defined by thyroid function using the SteelDwass test. Values of $P<.05$ were considered statistically significant.

\section{Results}




\section{Patient characteristics}

We have included 75 preterm and 27 term infants, 55 boys, 47 girls; (GA, 164290 days (23-41 weeks); CA, 6-134 days) without severe intracranial abnormalities in this study (Supplementary Material 1). Among 102 infants, 12 infants had subtle intracranial hemorrhage (intraventricular, subarachnoid, subdural, and cerebellar hemorrhage) and one infant had hydrocephalus. One term infant was excluded for GA analysis because the precise GA was unable to be determined. Characteristics of the included patients are listed in Table 1. Representative cases are shown in Figures 2. Among 102 infants, 6 infants had received treatment with L-thyroxine (L-T4) at the time of MRI, and 2 of 6 corresponding mothers had been diagnosed with thyroid dysfunction.

Relationships between pituitary signals and age and $B W$

Intraclass Correlation Coefficients (ICC) between two raters were excellent (Supplementary Material 2). Both $\mathrm{AP}_{\text {mean }} /$ pons and $\mathrm{PP}$ mean/pons correlated positively with GA ( $\rho=0.62, P<.001$ and $\rho=0.49, P<.001$, respectively), negatively with $\mathrm{CA}$ ( $\rho=-$ $0.86, P<.001$ and $\rho=-0.70, P<.001$, respectively $)$, negatively with GA $+\mathrm{CA}(\rho=-0.46$, $P<.001$ and $\mathrm{r}=-0.38, P<.001$, respectively $)$, and positively with $\mathrm{BW}(\rho=0.74, P<.001$ 
and $\rho=0.63, P<.001$, respectively) (Figure 3). "r" and " $\rho$ " represent Pearson's

correlation coefficient, Spearman's rank correlation coefficient, respectively.

Correlation of $\mathrm{AP}_{\max } /$ pons and $\mathrm{PP}_{\max } /$ pons with $\mathrm{GA}, \mathrm{CA}, \mathrm{GA}+\mathrm{CA}$, and $\mathrm{BW}$

were also shown in Figure 4. AP $\max /$ pons correlated positively with GA $(\rho=0.68$, $P<.001)$, and negatively with $\mathrm{CA}(\rho=-0.85, P<.001)$. AP $\max /$ pons correlated negatively with GA+CA $(\mathrm{r}=-0.34, P<.001)$. AP $\max /$ pons also correlated positively with BW $(\rho=0.74, P<.001) . P_{\max } /$ pons correlated positively with GA $(\rho=0.51, P<.001)$, and negatively with $\mathrm{CA}(\rho=-0.68, P<.001)$ and $\mathrm{GA}+\mathrm{CA}(\mathrm{r}=-0.35, P<.001) . \mathrm{PP}_{\max } /$ pons correlated positively with BW $(\rho=0.61, P<.001)$.

Relationships between thyroid signal and age and $B W$

$\mathrm{T}_{\text {mean }} /$ cord correlated positively with GA $(\rho=0.48, P<.001)$, negatively with CA $(\rho=-0.59, P<.001)$, negatively with GA+CA $(\rho=-0.22, P=.03)$, and positively with BW $(\rho=0.55, P<.001)($ Figure 3$)$.

Correlation of $\mathrm{T}_{\max } /$ cord with $\mathrm{GA}, \mathrm{CA}, \mathrm{GA}+\mathrm{CA}$, and $\mathrm{BW}$ were also shown in Figure 4 . $\mathrm{T}_{\max } /$ cord correlated positively with GA $(\rho=0.59, P<.001)$, and negatively with CA $(\rho=-0.70, P<.001)$ and with $\mathrm{GA}+\mathrm{CA}(\rho=-0.22, P=.03) . \mathrm{T}_{\max } /$ cord correlated positively with BW $(\rho=0.68, P<.001)$. 
Relationships between pituitary volume and age, $B W$, and signal

AP_vol correlated positively with GA $(\rho=0.68, P<.001)$ and negatively with

CA $(\rho=-0.72, P<.001)$, but showed no correlation with GA+CA $(\rho=-0.01, P=.95)$.

AP_vol correlated positively with BW $(\rho=0.73, P<.001)$ (Figure 5). AP_vol correlated positively with $\mathrm{AP}_{\text {mean }} /$ pons $(\rho=0.55, P<.001)$ and $\mathrm{AP}_{\max } /$ pons $(\rho=0.54, P<.001)$ (Figure $6)$.

Relationships between thyroid volume and age, $B W$, and signal

T_vol correlated positively with GA $(\rho=0.50, P<.001)$ and negatively with CA $(\rho=-0.54, P<.001)$, but showed no correlation with GA+CA $(\rho=-0.05, P=.64) . \mathrm{T}_{-}$vol correlated positively with BW $(\rho=0.61, P<.001)$ (Figure 5). T_vol correlated positively with $\mathrm{T}_{\text {mean }} / \operatorname{cord}(\rho=0.54, P<.001)$ and $\mathrm{T}_{\max } / \operatorname{cord}(\rho=0.58, P<.001)$ (Figure 6$)$.

Relationship between pituitary and thyroid signal

$\mathrm{AP}_{\text {mean }} /$ pons correlated positively with $\mathrm{T}_{\text {mean }} / \operatorname{cord}(\rho=0.61, P<.001)$ and $\mathrm{AP}_{\max } /$ pons correlated positively with $\mathrm{T}_{\max } / \operatorname{cord}(\rho=0.67, P<.001)$, respectively. (Figure $6)$. 
Relationship between female and male infants

We have also performed statistical analysis of pituitary and thyroid signals, pituitary and thyroid volumes with genders, and no statistically significant difference was seen between genders (Table 2, Supplementary Material 3, 4).

\section{Relationship between term and preterm infants}

Pituitary and thyroid signals, pituitary and thyroid volumes were compared between term and preterm infants. $\mathrm{AP}_{\operatorname{mean}} /$ pons, $\mathrm{AP} \max /$ pons, $\mathrm{T}_{\max } /$ cord were significantly higher in term infants than in preterm infants. $\mathrm{PP}_{\text {mean }} /$ pons, $\mathrm{PP}$ max $/$ pons and

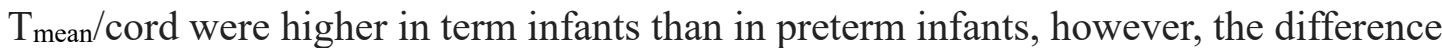
was not statistically significant. AP_vol and T_vol were significantly larger in term infants than in preterm infants (Table 3).

Thyroid function (TSH)

$\mathrm{T}_{\max } /$ cord was significantly higher in Group D than in Groups $\mathrm{A}, \mathrm{B}$, and C $(P=.003, P=.004$, and $P=.007$, respectively) (Figure 7). T_vol was significantly larger in Group D than in Groups A, B, and C $(P=.02, P=.002$, and $P=.002$, respectively) 
(Figure 7). Days of each thyroid function group are shown in Supplementary Material 5. The median of GA of A, B, C and D are 191, 238, 227 and 261 days, respectively. The median of CA of A, B, C and D are $89,44,38.5$ and 20 days, respectively.

\section{Discussion}

We investigated the potential relationship between intensity and volume of the pituitary and thyroid glands on 3D T1-weighted PETRA, which may reflect maturation of the HPT axis in the cohort of 102 neonates and infants. We chose pons for the reference of pituitary gland signal because pons is the nearest central nervous system (CNS) region (15), and we also chose cervical cord for the reference of thyroid gland because spinal cord is CNS part located near to the thyroid glands. The results showed that both signal and volume correlated with GA, CA, GA+CA, and BW.

Our 3D VOI analysis revealed that $\mathrm{AP}_{\text {mean }} /$ pons, $\mathrm{AP}_{\max } /$ pons, $\mathrm{PP}_{\text {mean }} /$ pons and $\mathrm{PP}_{\max } /$ pons correlated negatively with $\mathrm{CA}$, similar to the previous report using 2D ROIs (15). The normal pituitary gland is hyperintense on T1-weighted imaging at birth, and this high signal is attributed to the lingering effects of maternal hormones (21). Increases in the number of prolactin cells are induced by estrogen from the placenta during and after the 25th gestational week, causing an increase in signal from the 
pituitary gland $(13,15)$. Postnatal reduction of estrogen is suggested to cause the signal decrease in the anterior pituitary gland after birth $(13,22)$. A lower signal for the pituitary gland in patients with short GA may be attributed to lower exposure to estrogen from the placenta. In addition, the effect of postnatal reductions in estrogen after birth may become large with longer CA. We also observed a negative correlation between pituitary gland ( $\mathrm{AP}_{\operatorname{mean}} /$ pons, $\mathrm{AP}_{\max } /$ pons, $\mathrm{PP}_{\text {mean }} /$ pons, and $\mathrm{PP}_{\max } /$ pons $)$ and $\mathrm{GA}+\mathrm{CA}$, which suggests that pituitary signal decreased proportionately after birth regardless of GA. CA thus decreases pituitary signal more extensively meanwhile GA increases pituitary signal.

Our study demonstrated that thyroid gland signals correlate positively with GA, negatively with CA and GA+CA, and positively with BW like pituitary signal. Thyroid hormones play critical roles in central nervous system development in the fetus, neonate and infant (1), and thyroid hormone deficiency during these periods leads to irreversible intellectual disability $(5,23)$. Neurogenesis, neuronal migration, synaptogenesis, glial cell differentiation, and myelination are dependent on thyroid hormone in the late pregnancy and postnatal periods (5). Several reports have demonstrated that low levels of free T4 are strongly associated with poor neurodevelopmental outcomes $(1,7,8)$. Thyroid hormone also stimulates growth hormone secretion (24). The rate of congenital 
hypothyroidism is higher in preterm and LBW newborns than in normal newborns (23), a finding partly ascribed to immaturity of the HPT axis. The HPT axis regulates metabolism and the fetal HPT axis begins to function after the first trimester. HPT axis maturation completes at term gestation $(1,2)$. Between 30 to 42 gestational weeks, there is a progressive increase in iodine, T4 and T3 contents, and thyroid gland hormone reserves increases three- to four-fold $(1,25)$. Abundant thyroglobulin and iodine in the colloid cysts of the thyroid gland may contribute to T1-shortening effects (26-28). The increase in $\mathrm{T}_{\text {mean }} /$ cord and $\mathrm{T}_{\max } /$ cord seen in this study may represent an increase in protein and iodine concentrations in thyroid gland. $\mathrm{T}_{\text {mean }} /$ cord and $\mathrm{T}_{\max } /$ cord showed the same tendency as $\mathrm{AP}_{\text {mean }} /$ pons, $\mathrm{AP}_{\max } /$ pons, $\mathrm{PP}_{\max } /$ pons and $\mathrm{PP}_{\text {mean }} /$ pons, and $\mathrm{AP}_{\text {mean }} /$ pons and $\mathrm{AP}_{\max } /$ pons correlated positively with $\mathrm{T}_{\text {mean }} /$ cord, $\mathrm{T}_{\max } /$ cord, respectively. Thyroid signal in neonates may thus also reflect maternal hormones and the neonatal HPT axis. Maximum signal ratios of thyroid gland $\left(\mathrm{T}_{\max } /\right.$ cord $)$ showed higher correlation with GA, CA, GA+CA and BW compared with mean signal ratio ( $\mathrm{T}_{\text {mean }} /$ cord), which may suggest $\mathrm{T}_{\max } /$ cord reflects thyroid maturation status better than $\mathrm{T}_{\text {mean }} /$ cord.

Pituitary volumetric results showed that AP_vol correlated positively with GA and BW and negatively with CA. The relationship between AP_vol and age was 
similar to that between $\mathrm{AP}_{\operatorname{mean}} /$ pons, $\mathrm{AP}_{\max } /$ pons and ages other than $\mathrm{GA}+\mathrm{CA}$. The pituitary gland is physiologically enlarged at birth, and the prominent large size of the pituitary is also attributed to the lingering effects of maternal hormones. Volume declines to a normal infant size in the next 8-10 weeks (21). Insufficient hormonal effect from the mother may cause small pituitary size in patients with short GA, and pituitary size is similarly smaller in patients with longer CA.

Thyroid volumetric results in this study showed positive correlation with GA and BW and negative correlation with CA. The relationship between $\mathrm{T}_{-}$vol and age was similar to that between $\mathrm{T}_{\text {mean }} /$ cord, $\mathrm{T}_{\max } /$ cord and ages other than GA+CA. Thyroid gland volume in the fetus, as assessed by ultrasound in premature infants, is less than $0.2 \mathrm{~mL}$ before 30 weeks and increases 8 - to 10 -fold between GA 30 to 42 weeks. In an extremely preterm age group, delivered at less than 28 weeks of gestation, an ultrasound study showed no association between mean thyroid volume and thyroid function or between mean thyroid volume and BW (6). Conversely, a weak correlation exists between thyroid volume and thyroid function in full-term infants (18). The distribution of thyroid volumes may have become relatively wide due to the inclusion of both term and preterm infants in our cohort. Thyroid volumetric results should be interpreted in light of geographic reasons related to iodine intake, ethnicity, and maternal factors (29), 
and our cohort consists of single ethnicity of Japanese who take much iodine from their food in general (30).

Thyroid function analysis showed significantly higher thyroid signal and significantly larger thyroid volume were observed in group D to which healthy neonates without TSH measurements belong. Thyroid signal and volume may represent thyroid function; however, CA of group D was less than the other groups. Thyroid signal and volume were lowest in the group A, patients diagnosed with hypothyroidism and given L-thyroxine, although statistical difference was not found between group A and group $\mathrm{B}-\mathrm{D}$, probably due to the limited number of group $\mathrm{A}(\mathrm{n}=6)$. Increasing the number of patients in group A is required for statistical comparison with the other groups in further studies.

Limitations

First, the MR examination was scheduled for a date around the term-equivalent 40 weeks (sum of GA and CA is 40 weeks) in most cases, but actual examination dates ranged from 244 to 319 days because of the general condition of patients or limited availability of MR examination slots. Second, no histopathological confirmation was obtained for pituitary gland or thyroid gland, so we could not identify underlying contributions to the correlations among the pituitary and thyroid glands with GA and 
CA. Third, the median of CA of each thyroid function group was not equivalent; therefore, a further prospective study with MR examination at a specific CA is required for a better understanding of the relationship between thyroid function and MR findings of the thyroid gland. Fourth, T1-PETRA is mainly used for pediatric patients for whom quiet scan is preferable, and reliability of signal on T1-PETRA has not been known. We confirmed high correlation between measured signal on T1-PETRA and theoretical T1 values (Supplementary Material 6). Fifth, we did not calculate the volume of the PP because of its small structure compared with the resolution of MRI. The posterior lobe of the pituitary gland is very small structure compared with the resolution of MRI and 3D VOI of PP was chosen to be a few voxels, therefore, we avoided the volume calculation for PP. On the other hand, we considered the signal intensity calculation of 3D VOI to be reliable because we found the high correlation of signal intensity of PP between $2 \mathrm{D}$ ROI created from the 3D VOI and the original 3D VOI $\left(\mathrm{R}^{2}=0.988\right)$ (Supplementary material 7). Sixth, no international guidelines have been set for thyroid function monitoring, and neonates are usually treated to keep thyroid stimulating hormone (TSH ) within the age-specific reference range (31). We did not treat TSH as a continuous value, because TSH may vary a little daily.

Conclusion 
Our 3D VOI analysis of the HPT axis showed that signal intensity of the anterior and posterior lobes of the pituitary and thyroid glands were positively correlated with GA and BW and negatively correlated with $\mathrm{CA}$ and $\mathrm{GA}+\mathrm{CA}$. The volume of the anterior lobes of the pituitary and thyroid glands correlated positively with GA and BW and negatively with CA. These relationships may lead to develop a model to detect abnormalities of HPT axis in neonates. 


\section{References}

1. Fisher DA. Thyroid system immaturities in very low birth weight premature infants. Semin Perinatol 2008;32:387-397.

2. Lee JH, Kim SW, Jeon GW, Sin JB. Thyroid dysfunction in very low birth weight preterm infants. Korean J Pediatr 2015;58:224-229.

3. Laurberg P. Thyroid function: Thyroid hormones, iodine and the brain-an important concern. Nat Rev Endocrinol 2009;5:475-476.

4. Burrow GN, Fisher DA, Larsen PR. Maternal and fetal thyroid function. N Engl J Med 1994;331:1072-1078.

5. Williams GR. Neurodevelopmental and neurophysiological actions of thyroid hormone. J Neuroendocrinol 2008;20:784-794.

6. Ng SM, Turner MA, Avula S. Ultrasound Measurements of Thyroid Gland Volume at 36 Weeks' Corrected Gestational Age in Extremely Preterm Infants Born before 28 Weeks' Gestation. Eur Thyroid J 2018;7:21-26.

7. Yamamoto A, Kawai M, Iwanaga K, et al. Response to thyrotropin-releasing hormone stimulation tests in preterm infants with transient hypothyroxinemia of prematurity. J Perinatol 2015;35:725-728.

8. Reuss ML, Paneth N, Pinto-Martin JA, Lorenz JM, Susser M. The relation of transient hypothyroxinemia in preterm infants to neurologic development at two years of age. $\mathrm{N}$ Engl J Med 1996;334:821-827.

9. Murphy $\mathrm{N}$, Hume R, van Toor $\mathrm{H}$, et al. The hypothalamic-pituitary-thyroid axis in preterm infants; changes in the first 24 hours of postnatal life. J Clin Endocrinol Metab 2004;89:2824-2831.

10. Walsh JM, Doyle LW, Anderson PJ, Lee KJ, Cheong JL. Moderate and late preterm birth: effect on brain size and maturation at term-equivalent age. Radiology 2014;273:232-240.

11. Saigal S, Doyle LW. An overview of mortality and sequelae of preterm birth from infancy to adulthood. Lancet 2008;371:261-269.

12. Benavente-Fernández I, Rodríguez-Zafra E, León-Martínez J, et al. Normal Cerebellar Growth by Using Three-dimensional US in the Preterm Infant from Birth to Termcorrected Age. Radiology 2018;288:254-261.

13. Cox TD, Elster AD. Normal pituitary gland: changes in shape, size, and signal intensity during the 1st year of life at MR imaging. Radiology 1991;179:721-724.

14. Okazaki T, Niwa T, Suzuki K, Shibukawa S, Imai Y. Age related signal changes of the pituitary stalk on thin-slice magnetic resonance imaging in infants. Brain Dev 2019;41:327-333. 
15. Kitamura E, Miki Y, Kawai M, et al. T1 signal intensity and height of the anterior pituitary in neonates: correlation with postnatal time. AJNR Am J Neuroradiol 2008;29:1257-1260.

16. Hori S, Taoka T, Ochi T, et al. Structures Showing Negative Correlations of Signal Intensity with Postnatal Age on T. Magn Reson Med Sci 2017;16:325-331.

17. Sari S, Sari E, Akgun V, et al. Measures of pituitary gland and stalk: from neonate to adolescence. J Pediatr Endocrinol Metab 2014;27:1071-1076.

18. Freire R, Monte O, Tomimori EK, et al. Sonographic evaluation of the thyroid size in neonates. J Clin Ultrasound 2015;43:224-229.

19. Aida N, Niwa T, Fujii Y, et al. Quiet T1-Weighted Pointwise Encoding Time Reduction with Radial Acquisition for Assessing Myelination in the Pediatric Brain. AJNR Am J Neuroradiol 2016;37:1528-1534.

20. Yushkevich PA, Piven J, Hazlett HC, et al. User-guided 3D active contour segmentation of anatomical structures: significantly improved efficiency and reliability. Neuroimage 2006;31:1116-1128.

21. Delman BN. Imaging of pediatric pituitary abnormalities. Endocrinol Metab Clin North Am 2009;38:673-698.

22. Wolpert SM, Osborne M, Anderson M, Runge VM. The bright pituitary gland--a normal MR appearance in infancy. AJNR Am J Neuroradiol 1988;9:1-3.

23. Hashemipour M, Hovsepian S, Ansari A, Keikha M, Khalighinejad P, Niknam N. Screening of congenital hypothyroidism in preterm, low birth weight and very low birth weight neonates: A systematic review. Pediatr Neonatol 2018;59:3-14.

24. Cabello G, Wrutniak C. Thyroid hormone and growth: relationships with growth hormone effects and regulation. Reprod Nutr Dev 1989;29:387-402.

25. van den Hove MF, Beckers C, Devlieger H, de Zegher F, De Nayer P. Hormone synthesis and storage in the thyroid of human preterm and term newborns: effect of thyroxine treatment. Biochimie 1999;81:563-570.

26. Nikoubashman O, Jablawi F, Dekeyzer S, et al. MRI Appearance of Intracerebral Iodinated Contrast Agents: Is It Possible to Distinguish Extravasated Contrast Agent from Hemorrhage? AJNR Am J Neuroradiol 2016;37:1418-1421.

27. Morales H, Lemen L, Samaratunga R, Nguyen P, Tomsick T. Effects of iodinated contrast on various magnetic resonance imaging sequences and field strength: Implications for characterization of hemorrhagic transformation in acute stroke therapy. World J Radiol 2016;8:588-593.

28. Ginat DT, Meyers SP. Intracranial lesions with high signal intensity on T1-weighted MR images: differential diagnosis. Radiographics 2012;32:499-516.

29. Klein RZ, Carlton EL, Faix JD, et al. Thyroid function in very low birth weight infants. 
Clin Endocrinol (Oxf) 1997;47:411-417.

30. Zava TT, Zava DT. Assessment of Japanese iodine intake based on seaweed consumption in Japan: A literature-based analysis. Thyroid Res 2011;4:14.

31. Léger J, Olivieri A, Donaldson M, et al. European Society for Paediatric Endocrinology consensus guidelines on screening, diagnosis, and management of congenital hypothyroidism. J Clin Endocrinol Metab 2014;99:363-384. 
Table 1. Characteristics of the included patients.

\begin{tabular}{|c|c|c|}
\hline \multicolumn{3}{|l|}{$\operatorname{Sex}[\mathrm{n}]$} \\
\hline Male & & 55 \\
\hline Female & & 47 \\
\hline \multicolumn{3}{|l|}{ Age [days] } \\
\hline GA & & 238 [201.5-261] \\
\hline $\mathrm{CA}$ & & $34.5[21-73.5]$ \\
\hline $\mathrm{GA}+\mathrm{CA}$ & & $280.9 \pm 16.0$ \\
\hline $\mathrm{BW}[\mathrm{g}]$ & & $1791[1115-2568]$ \\
\hline \multicolumn{3}{|l|}{ Signal ratio } \\
\hline \multirow{2}{*}{ Anterior pituitary } & $\mathrm{AP}_{\text {mean }} /$ pons & $1.37[1.25-1.53]$ \\
\hline & $\mathrm{AP}_{\max } /$ pons & $1.68 \pm 0.25$ \\
\hline \multirow{2}{*}{ Posterior pituitary } & $\mathrm{PP}_{\text {mean }} /$ pons & $1.85 \pm 0.26$ \\
\hline & $\mathrm{PP}_{\max } /$ pons & $2.34 \pm 0.43$ \\
\hline \multirow{2}{*}{ Thyroid } & $\mathrm{T}_{\text {mean }} /$ cord & $1.32[1.20-1.42]$ \\
\hline & $\mathrm{T}_{\max } /$ cord & 1.70 [1.49-1.89] \\
\hline \multirow{4}{*}{$\begin{array}{l}\text { Tmean/cord mean } \\
\text { broken up by } \\
\text { thyroid function } \\
\text { group }\end{array}$} & $A(n=6)$ & $1.16[1.04-1.32]$ \\
\hline & $B(n=31)$ & $1.26[1.19-1.37]$ \\
\hline & $C(n=40)$ & $1.29[1.17-1.38]$ \\
\hline & $D(n=25)$ & $1.44[1.33-1.49]$ \\
\hline \multicolumn{3}{|l|}{ Volume [ml] } \\
\hline Anterior pituitary & AP_vol & $56.6[42.2-74.9]$ \\
\hline Thyroid & T_vol & 634.5 [486.2-798.8] \\
\hline \multirow{4}{*}{$\begin{array}{l}\text { T_vol } \\
\text { broken up by } \\
\text { thyroid function } \\
\text { group }\end{array}$} & $A(n=6)$ & 397 [220-653] \\
\hline & $B(n=31)$ & 564 [437-690] \\
\hline & $C(n=40)$ & 614 [493-717] \\
\hline & $D(n=25)$ & 827 [640-1009] \\
\hline
\end{tabular}


GA, gestational age; CA, chronological age; BW, birth weight; AP, anterior pituitary;

PP, posterior pituitary; T, thyroid; AP_vol, volume of anterior pituitary; T_vol, volume of thyroid gland. Average \pm standard deviation was used when the data shows normal distribution, otherwise, median value with 25 and 75 percentiles were used. 
Table 2. Signal ratio and volume of pituitary and thyroid gland in female and male infants.

\begin{tabular}{|c|c|c|c|c|}
\hline & & Female $(n=47)$ & Male $(n=55)$ & $P$ value \\
\hline \multicolumn{5}{|l|}{ Signal ratio } \\
\hline \multirow{2}{*}{ Anterior pituitary } & $\mathrm{AP}_{\text {mean }} /$ pons & $1.39 \pm 0.18$ & $1.4 \pm 0.17$ & 0.77 \\
\hline & $\mathrm{AP}_{\max } /$ pons & $1.68 \pm 0.25$ & $1.69 \pm 0.25$ & 0.78 \\
\hline \multirow{2}{*}{ Posterior pituitary } & $\mathrm{PP}_{\text {mean }} /$ pons & $1.9[1.55-2.02]$ & $1.87 \pm 0.26$ & 0.71 \\
\hline & $\mathrm{PP}_{\max } /$ pons & $2.30 \pm 0.43$ & $2.38 \pm 0.42$ & 0.32 \\
\hline \multirow{2}{*}{ Thyroid } & $\mathrm{T}_{\text {mean }} /$ cord & $1.29[1.17-1.42]$ & $1.34 \pm 0.20$ & 0.41 \\
\hline & $\mathrm{T}_{\max } /$ cord & $1.68[1.43-1.86]$ & 1.70 [1.50-1.95] & 0.37 \\
\hline \multicolumn{5}{|l|}{ Volume [ml] } \\
\hline Anterior pituitary & AP_vol & $61.2 \pm 20.0$ & $52.9[39.2-76.9]$ & 0.41 \\
\hline Thyroid & T_vol & $650.8 \pm 228.6$ & 661.1 [483.6-806.4] & 0.95 \\
\hline
\end{tabular}

$\mathrm{AP}$, anterior pituitary; PP, posterior pituitary; T, thyroid; $\mathrm{AP} \_$vol, volume of anterior pituitary; T_vol, volume of thyroid gland. Average \pm standard deviation was used when the data shows normal distribution, otherwise, median value with 25 and 75 percentiles were used. 
Table 3. Signal ratio and volume of pituitary and thyroid gland in term and preterm infants.

\begin{tabular}{|c|c|c|c|c|}
\hline & & Term $(n=27)$ & Preterm $(n=75)$ & $P$ value \\
\hline \multicolumn{5}{|l|}{ Signal ratio } \\
\hline \multirow{2}{*}{ Anterior pituitary } & $\mathrm{AP}_{\text {mean }} /$ pons & $1.49 \pm 0.15$ & $1.34[1.20-1.50]$ & 0.001 \\
\hline & $\mathrm{AP}_{\max } /$ pons & $1.84 \pm 0.21$ & $1.58[1.43-1.84]$ & $<.001$ \\
\hline \multirow{2}{*}{ Posterior pituitary } & $\mathrm{PP}_{\text {mean/pons }}$ & $1.95[1.80-2.03]$ & $1.81 \pm 0.27$ & 0.07 \\
\hline & $\mathrm{PP}_{\max } /$ pons & $2.50[2.28-2.60]$ & $2.28 \pm 0.45$ & 0.10 \\
\hline \multirow{2}{*}{ Thyroid } & $\mathrm{T}_{\text {mean }} /$ cord & $1.38 \pm 0.16$ & $1.28[1.17-1.41]$ & 0.06 \\
\hline & $\mathrm{T}_{\max } /$ cord & $1.79[1.68-2.00]$ & $1.62[1.43-1.84]$ & 0.001 \\
\hline \multicolumn{5}{|l|}{ Volume [ml] } \\
\hline Anterior pituitary & $\mathrm{AP}_{-}$vol & $81.8 \pm 15.7$ & $51.7 \pm 17.8$ & $<.001$ \\
\hline Thyroid & T_vol & 803.5 [666.5-955.8] & $593.1 \pm 202.2$ & $<.001$ \\
\hline
\end{tabular}

AP, anterior pituitary; PP, posterior pituitary; T, thyroid; AP_vol, volume of anterior pituitary; T_vol, volume of thyroid gland. Average \pm standard deviation was used when the data shows normal distribution, otherwise, median value with 25 and 75 percentiles were used. 


\section{Figure legends}

\section{Figure 1}

Representative images of volumes of interest for the anterior pituitary (red), pons (yellow), thyroid (blue), and cord (yellow). Enlarged view of pituitary gland (a, b, c) and thyroid gland (d, e) on multiplanar reconstructed (MPR) images of T1-weighte Pointwise Encoding Time Reduction with Radial Acquisition (PETRA) : axial, a, e; sagittal, b; and coronal, c, d.

\section{Figure 2}

A male term infant, gestational age (GA) 263 days, chronological age (CA) 8 days (a, b, c, and d). Both the anterior (white arrow) and posterior pituitary (black arrow) are hyperintense on T1-weighted Pointwise Encoding Time Reduction with Radial Acquisition (T1-PETRA). The thyroid (arrowheads) is also hyperintense on T1-PETRA. A female preterm infant, GA 177 days, CA 102 days (e, f, g, and h). Anterior pituitary (white arrow) is slightly hyperintense and posterior pituitary (black arrow) is slightly hyperintense on T1-PETRA compared with pons. Thyroid (arrowheads) is relatively hyperintense on T1-PETRA compared with spinal cord. The signals of pituitary gland and thyroid gland are lower intense and the volumes are smaller compared with those of term 
infant. Enlarged view of pituitary gland (a, b, e, and f) and thyroid gland (c, d, g, and h) on multiplanar reconstructed (MPR) images of T1-PETRA: axial, a, c, e, and g; sagittal, b, f; and coronal, d, h.

\section{Figure 3}

Scatter plots of mean signal ratios of pituitary gland (APmean/pons, $\mathrm{PP}_{\text {mean }} /$ pons) and thyroid gland (Tmean/cord) vs. GA, CA, GA+CA, and BW. $\mathrm{AP}=$ anterior pituitary, $\mathrm{PP}=$ posterior pituitary, $\mathrm{BW}=$ birth weight, $\mathrm{GA}=$ gestational age, $\mathrm{CA}=$ chronological age. $\mathrm{AP}_{\text {mean }} /$ pons, $\mathrm{PP}_{\text {mean }} /$ pons, and $\mathrm{T}_{\text {mean }} /$ cord $=$ mean signal ratios of $\mathrm{AP}, \mathrm{PP}$, and thyroid, respectively.

\section{Figure 4}

Scatter plots of maximum signal ratios of pituitary gland (AP $\mathrm{max}_{\mathrm{m}} / \mathrm{pons}$, $\mathrm{PP}_{\max } /$ pons) and thyroid gland $\left(\mathrm{T}_{\max } /\right.$ cord $)$ vs. GA, CA, GA+CA, and $\mathrm{BW} . \mathrm{AP}=$ anterior pituitary, $\mathrm{PP}=$ posterior pituitary, $\mathrm{BW}=$ birth weight, $\mathrm{GA}=$ gestational age, $\mathrm{CA}=$ chronological age $. \mathrm{AP}_{\max } /$ pons, $\mathrm{PP}_{\max } /$ pons, and $\mathrm{T}_{\max } /$ cord $=$ maximum signal ratios of AP, PP, and thyroid, respectively. 


\section{Figure 5}

Scatter plots of the volume of the pituitary gland (AP_vol) and the thyroid gland (T_vol) vs. GA, CA, GA+CA, and BW.

\section{Figure 6}

Scatter plots of volume of the signal ratios of anterior pituitary gland (AP $\mathrm{mean}_{\text {m }} /$ pons, $\mathrm{AP}_{\max } /$ pons) and thyroid gland ( $\mathrm{T}_{\text {mean }} /$ cord, $\mathrm{T}_{\max } /$ cord $)$ vs. pituitary gland (AP_vol) and thyroid gland (T_vol) volume. Scatter plots of signal ratio of APmean/pons and $\mathrm{T}_{\operatorname{mean}} /$ cord, $\mathrm{AP}_{\max } /$ pons and $\mathrm{T}_{\max } /$ cord are also shown.

\section{Figure 7}

Signal ratios for maximum thyroid gland ( $\left.\mathrm{T}_{\max } / \mathrm{cord}\right)$ from the four thyroid function groups (A-D). Note that Group A represents patients diagnosed with hypothyroidism (thyroid stimulating hormone $(\mathrm{TSH})>10 \mu \mathrm{IU} / \mathrm{ml}$ ) and receiving Lthyroxine. Group B represents patients with TSH level $>5 \mu \mathrm{IU} / \mathrm{ml}$, Group C represents patients with TSH $\leq 5 \mu \mathrm{IU} / \mathrm{ml}$, and Group D represents patients assessed as healthy (no TSH measurement performed). Volumes of thyroid gland ( $T_{-}$vol) for the four thyroid function groups are also shown (Groups A-D). 
Figure 1
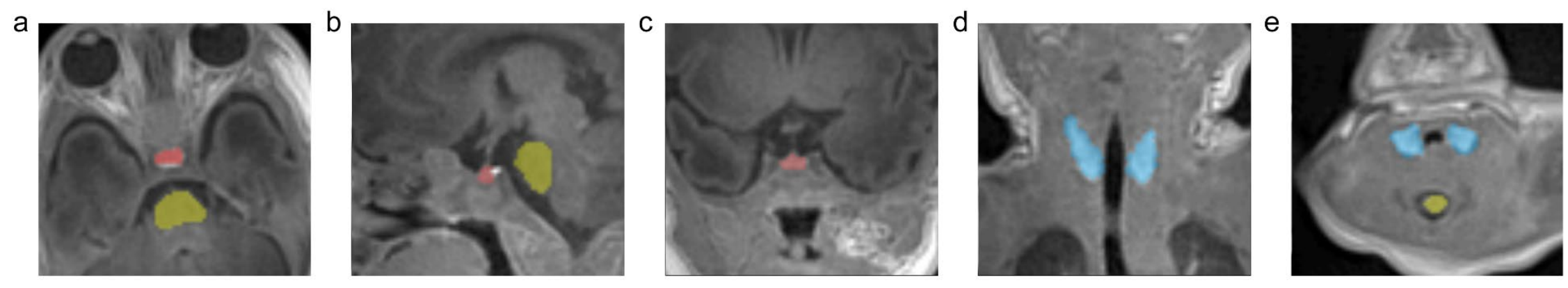
Figure 2

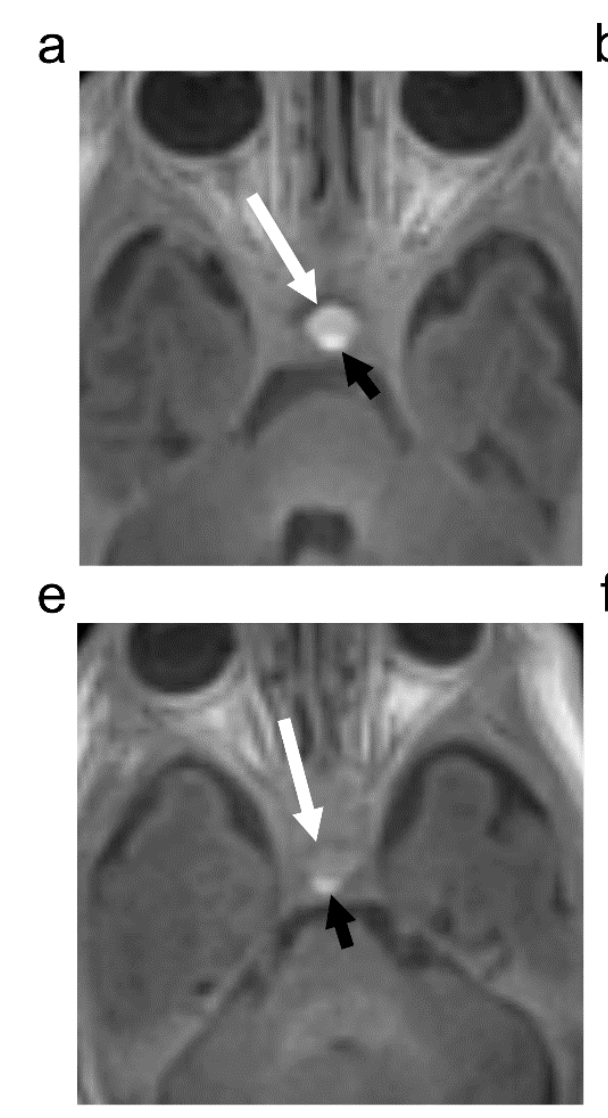

b
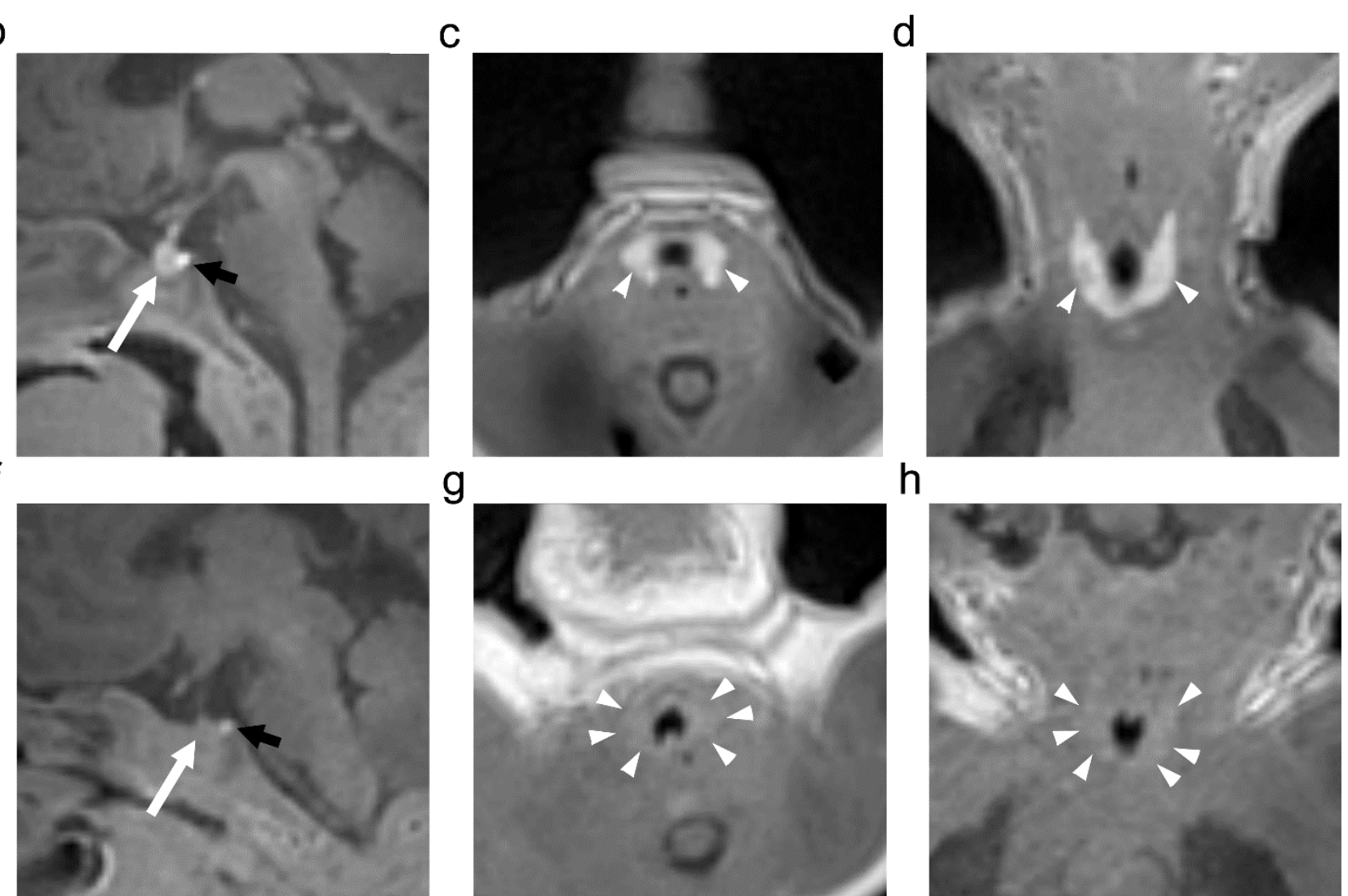


\section{Figure 3}
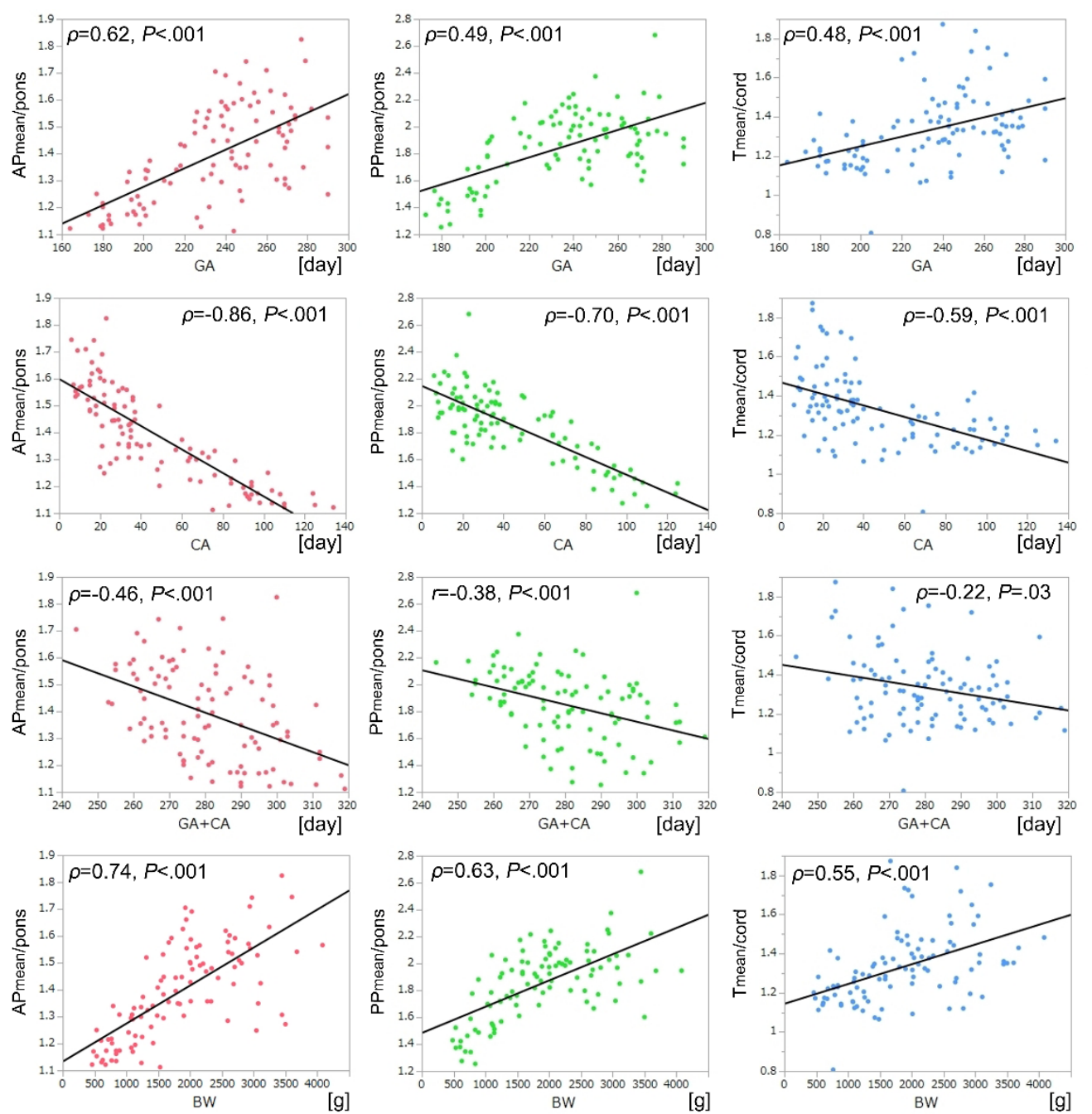


\section{Figure 4}
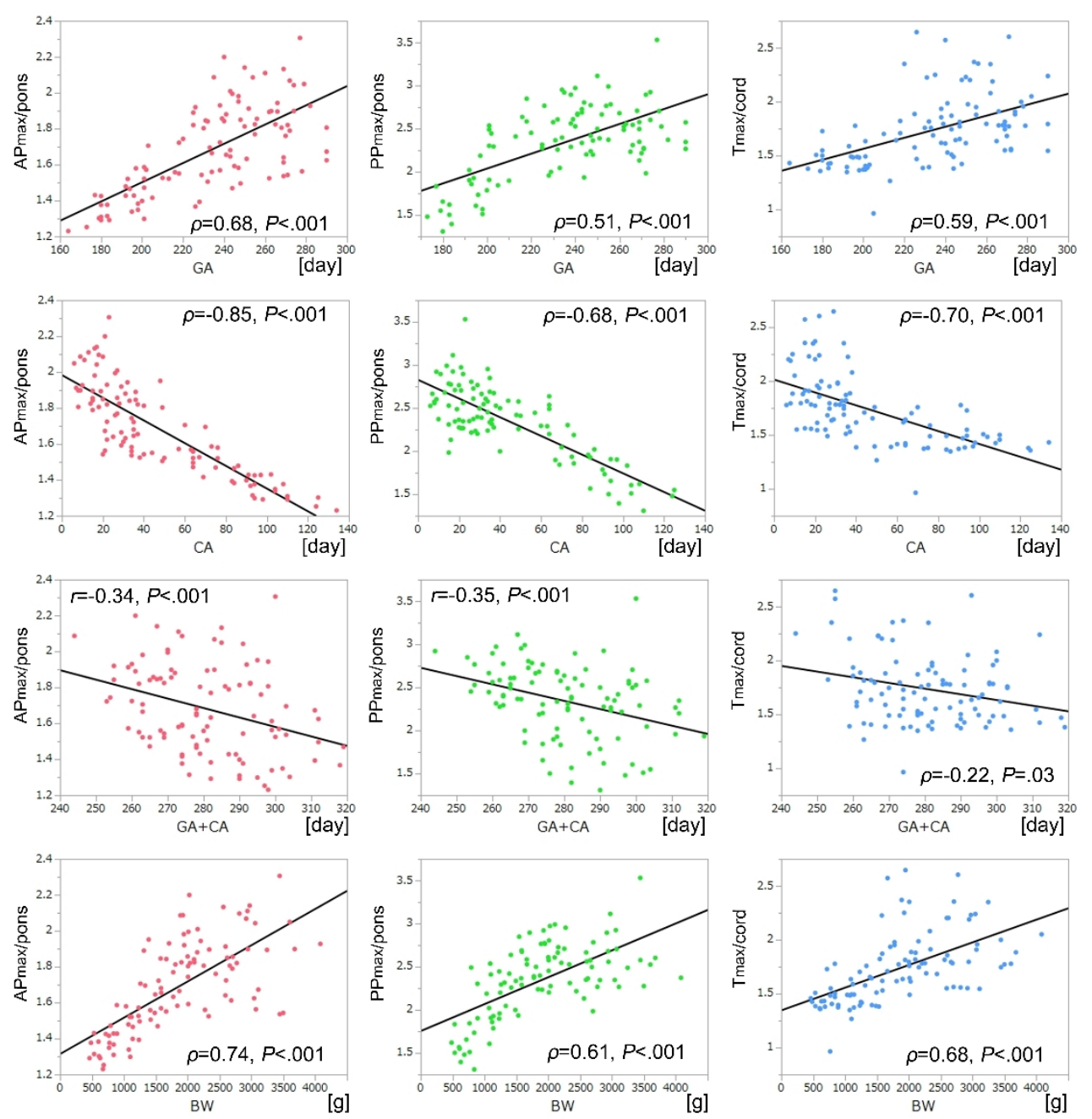


\section{Figure 5}
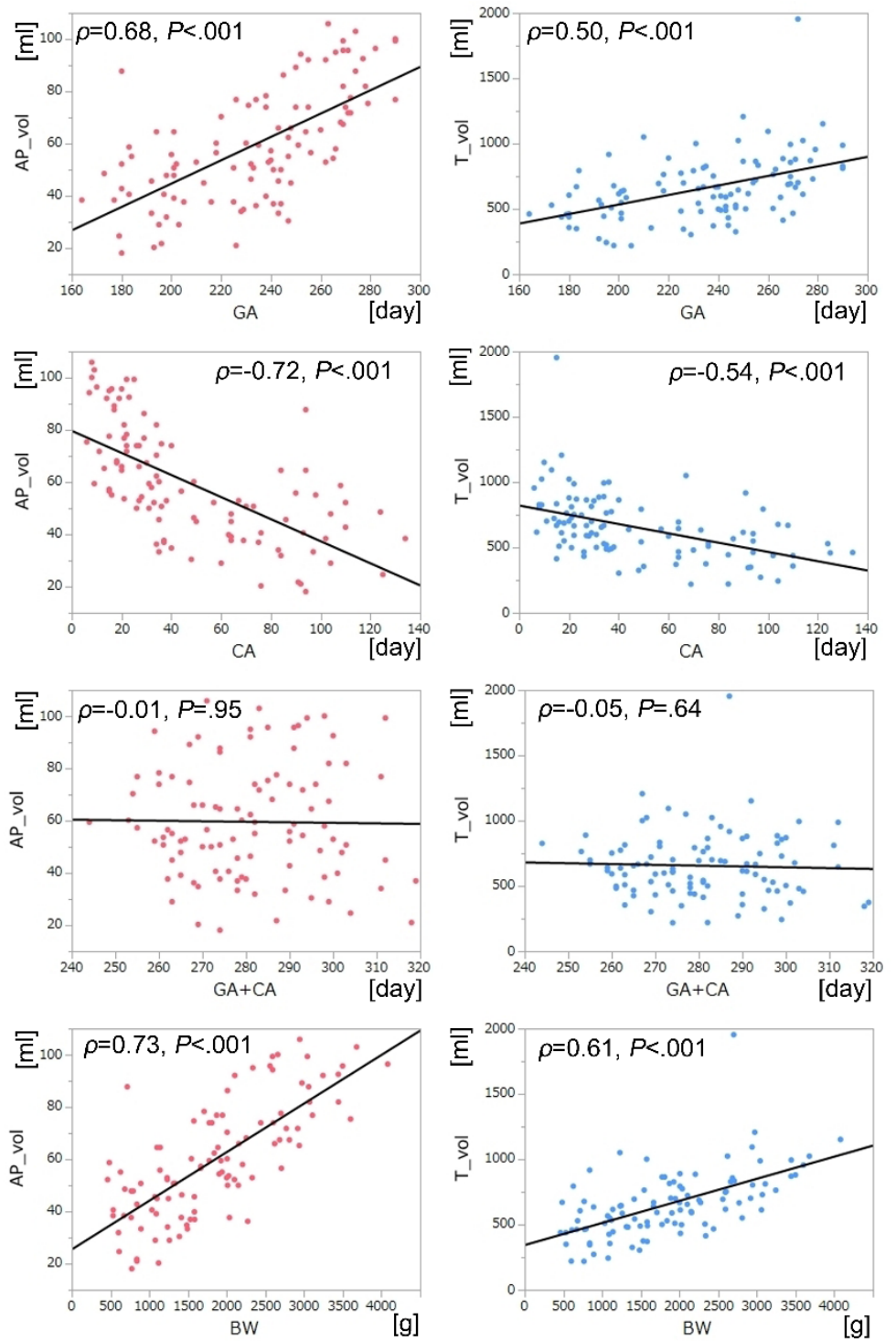


\section{Figure 6}
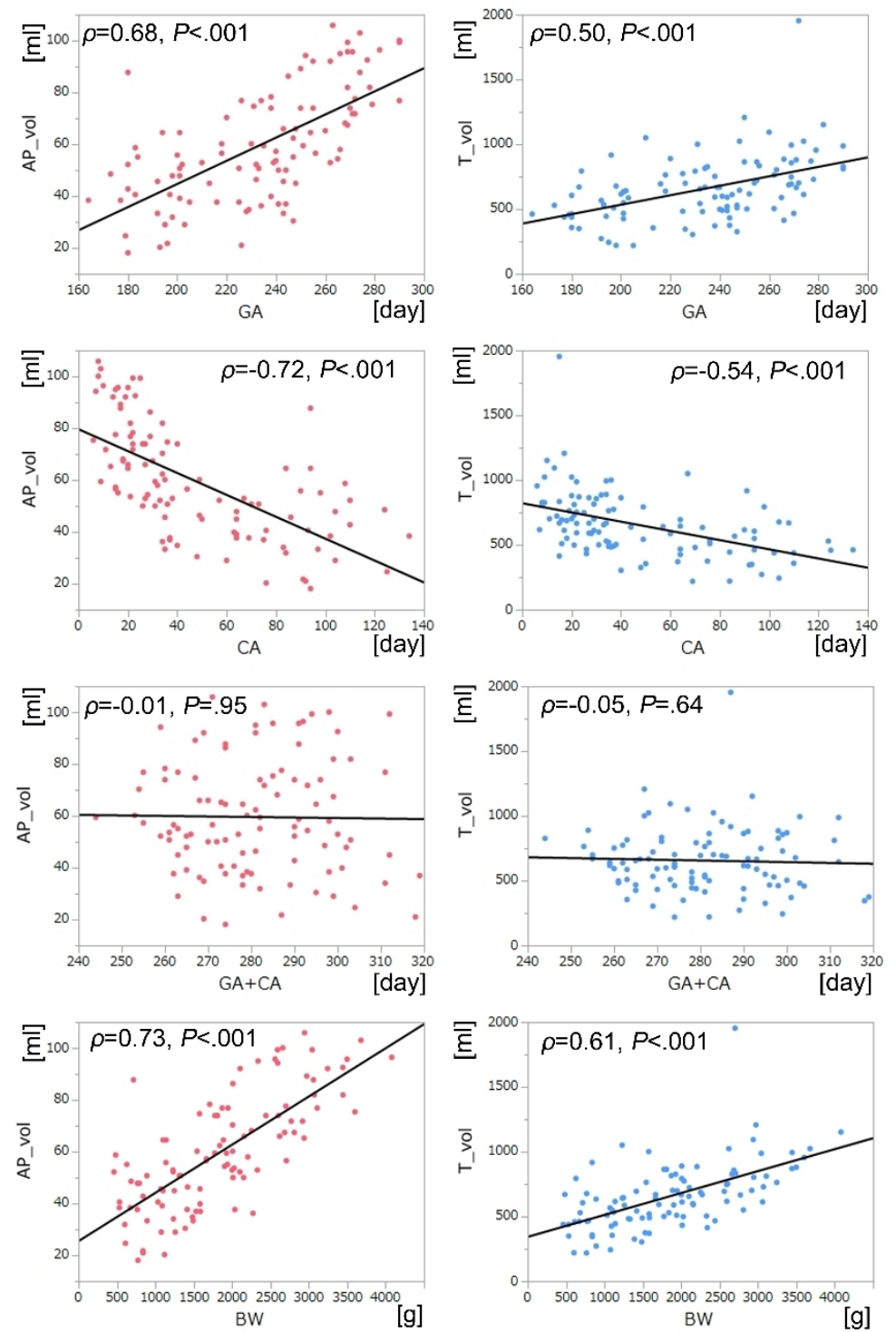


\section{Figure 7}
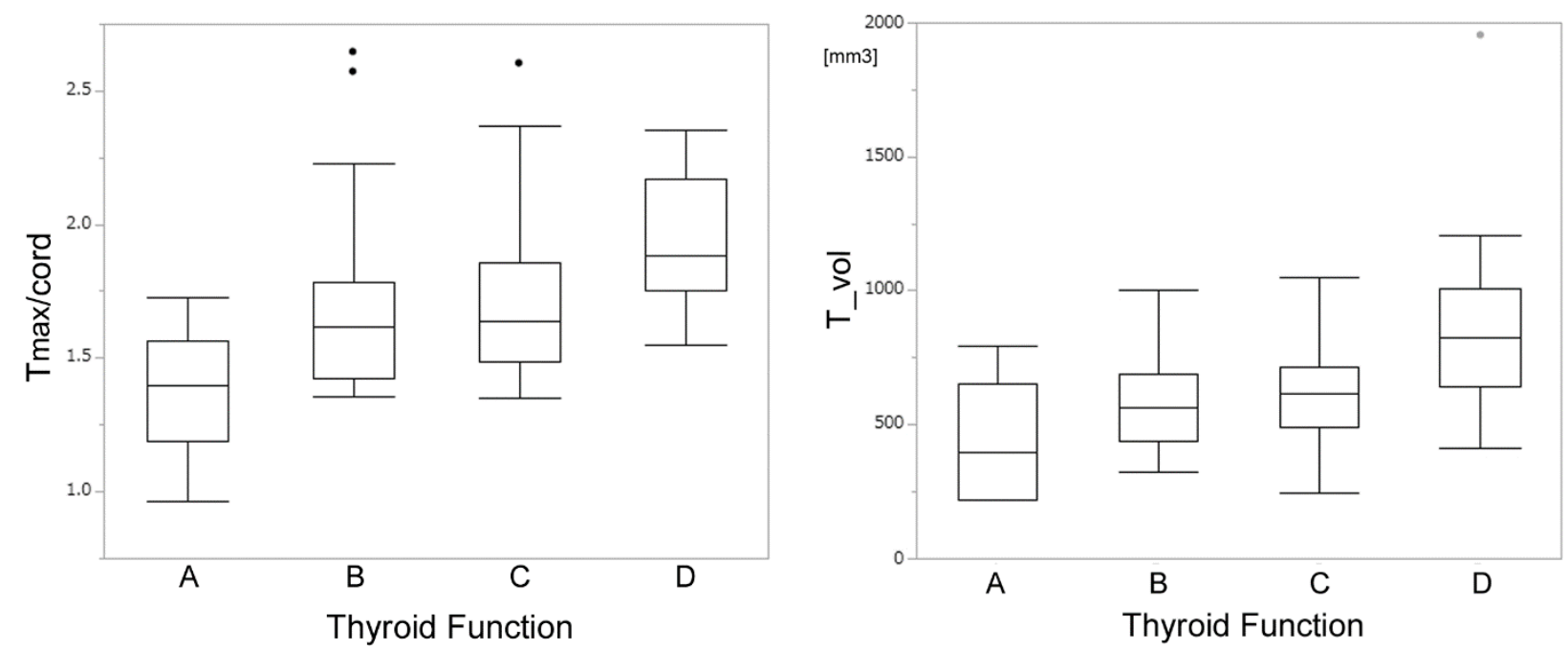


\section{Enrollment}

Preterm infants $(n=76)$ and term infants $(n=34)$

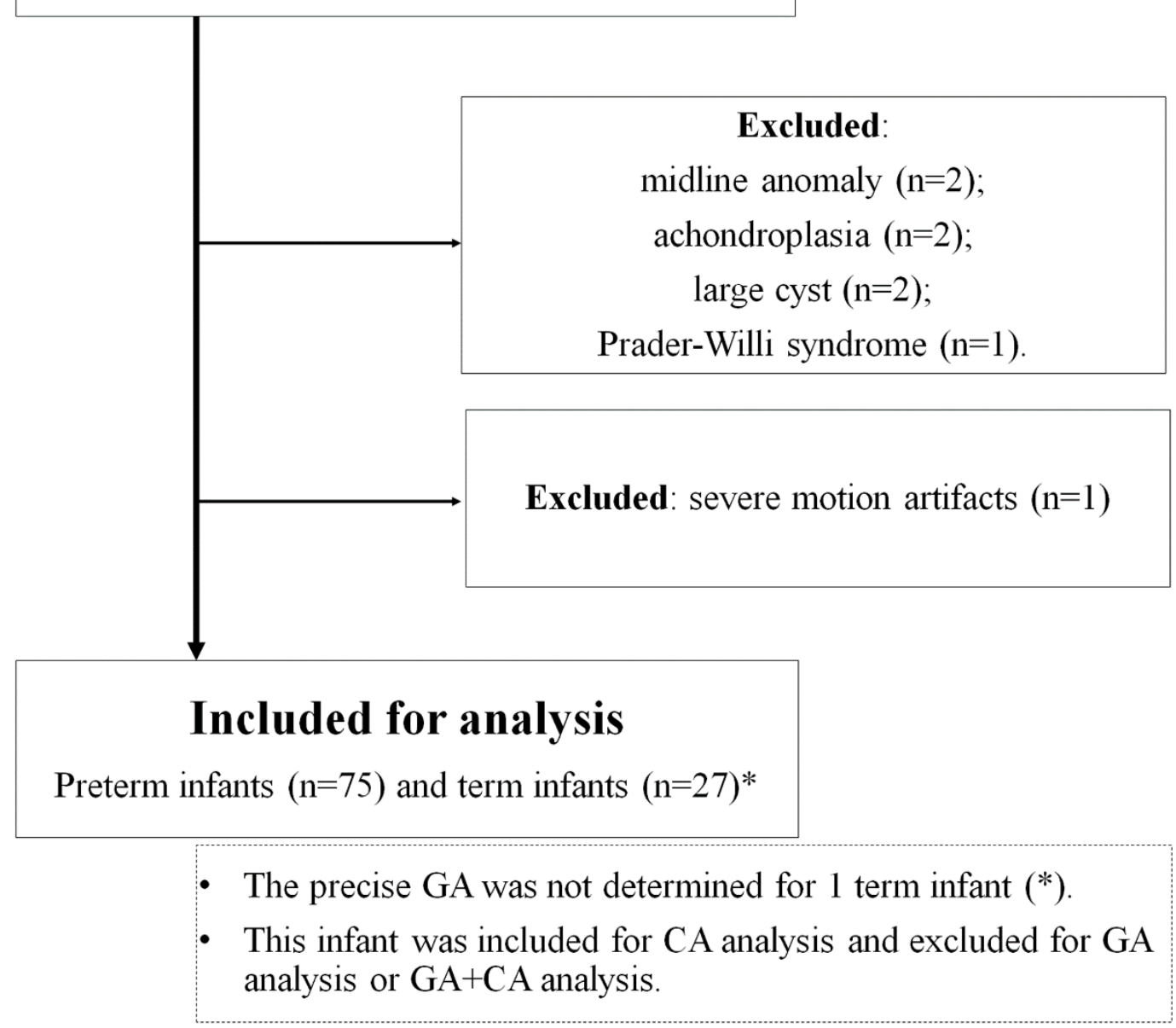

\section{Supplementary Material 1}

Inclusion and exclusion criteria for this study. 


\section{Supplementary Material 2}

ICCs between two raters were shown.

\begin{tabular}{|c|c|}
\hline Signal ratio & \\
\hline $\mathrm{AP}_{\text {mean }} /$ pons & 0.9974 \\
\hline $\mathrm{AP}_{\max } /$ pons & 0.9849 \\
\hline $\mathrm{PP}_{\text {mean }} /$ pons & 0.9868 \\
\hline $\mathrm{PP}_{\max } /$ pons & 0.9998 \\
\hline $\mathrm{T}_{\text {mean }} /$ cord & 0.9991 \\
\hline $\mathrm{T}_{\text {max }} /$ cord & 0.9988 \\
\hline Volume $[\mathrm{ml}]$ & \\
\hline $\mathrm{AP}_{-} \mathrm{vol}$ & 0.9868 \\
\hline $\mathrm{T}_{\text {_vol }}$ & 0.9930 \\
\hline
\end{tabular}




\section{Supplementary Material 3}

We have also performed statistical analysis of $\mathrm{AP}$ mean/pons, $\mathrm{PP}_{\text {mean }} /$ pons and

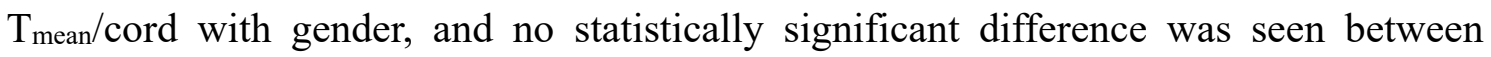
genders. The distribution plots with gender are shown as below.
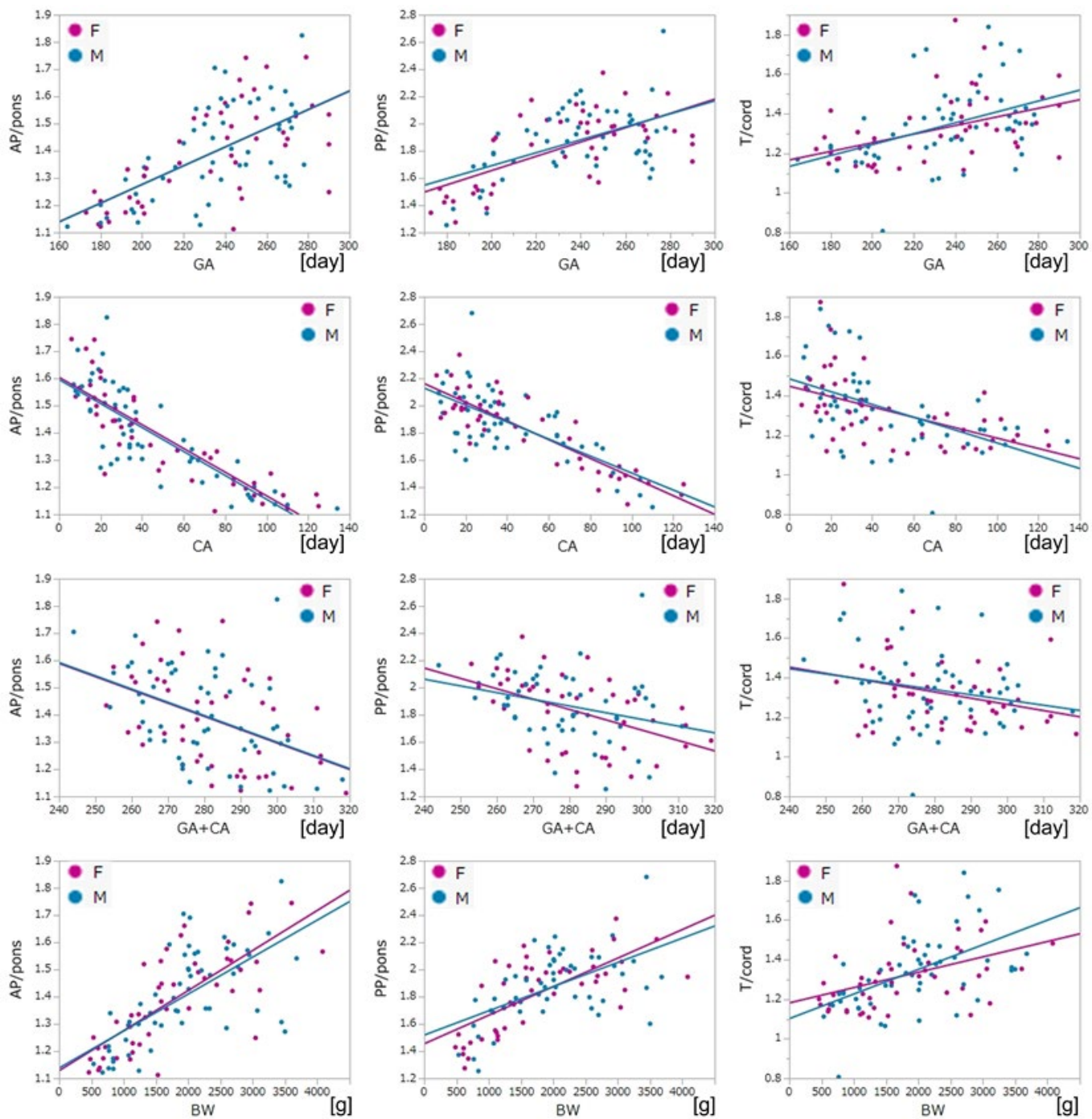


\section{Supplementary Material 4}

We have also performed statistical analysis of AP_vol and T_vol with gender, and no statistically significant difference was seen between genders. The distribution plots with gender are shown as below.
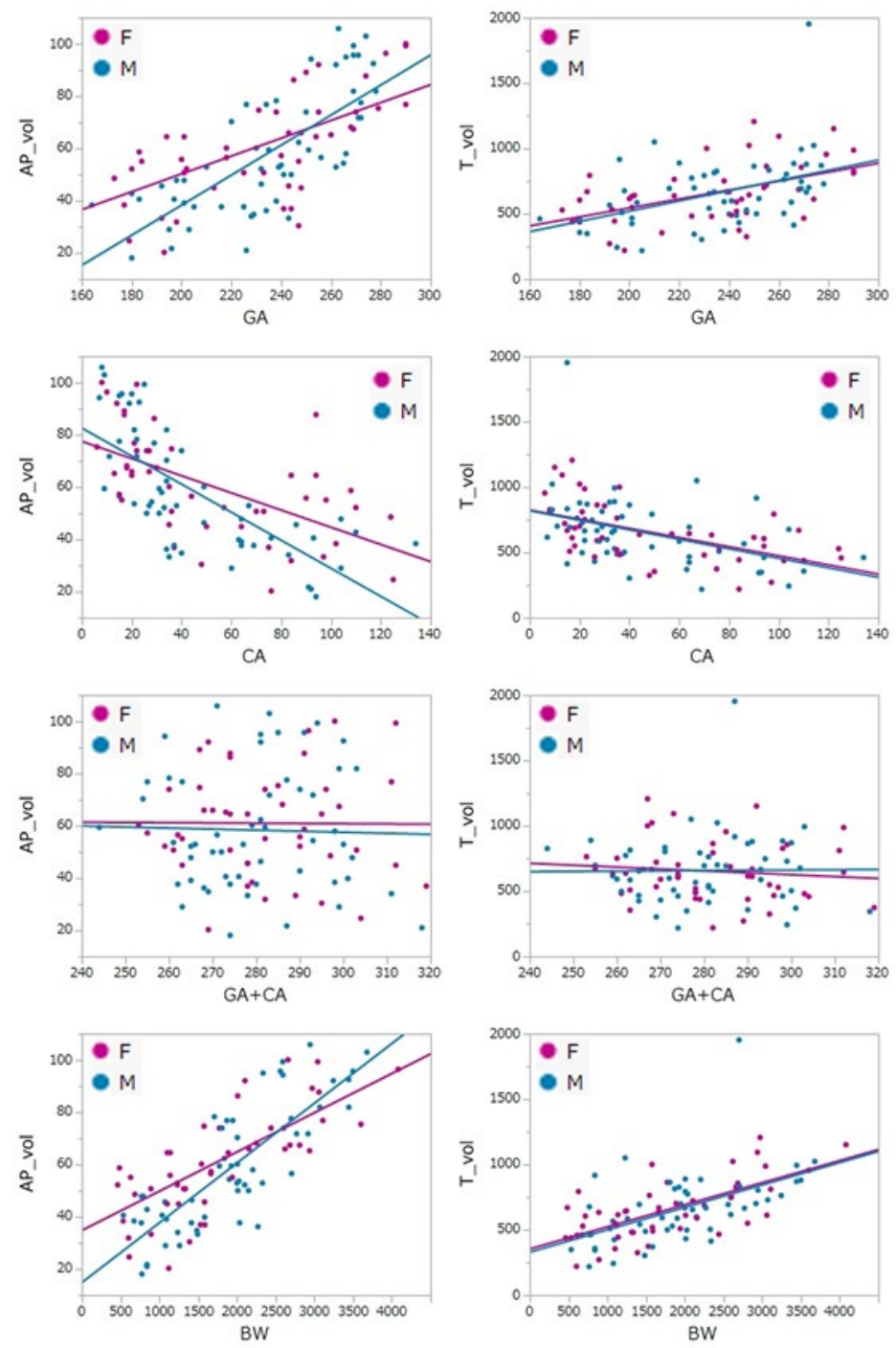


\section{Supplementary Material 5}

Days of each thyroid function group (A, B, C and D) are shown as below.

\begin{tabular}{|l|c|c|c|}
\hline [days] & GA & CA & GA+CA \\
\hline A & $191[179.3-207]$ & $89[64.3-99]$ & $276.5[271.3-282]$ \\
\hline B & $238[201-247]$ & $44[26-75]$ & $278[265-295]$ \\
\hline C & $227[197.3-253.5]$ & $38.5[25.5-85.5]$ & $278.5[269.3-293.8]$ \\
\hline D & $261[245.5-272]$ & $20[14-28.5]$ & $281[267.3-292.8]$ \\
\hline
\end{tabular}




\section{Supplementary Material 6}

T1-PETRA is mainly used for pediatric patients for whom quiet scan is preferable. As far as we know, there is no phantom study on T1-PETRA, we conducted phantom study on T1-PETRA. We scanned T1-PETRA for ISMRM-NIST phantom because the phantom contained spheres with known theoretical T1 values. The results are shown below. Signal intensity of AP, PP, T, pons, and cord on T1-PETRA [AU] of our cohort were shown.

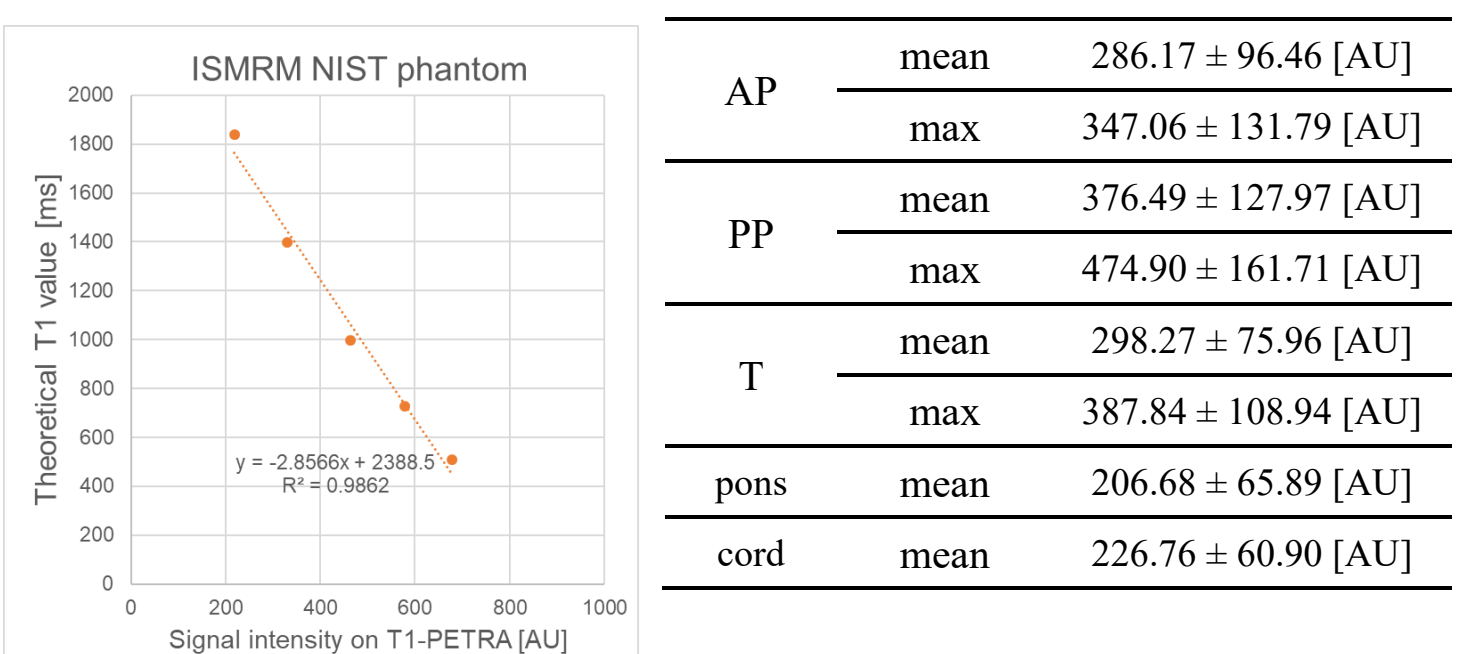

The plots of measured signal intensity on T1-PETRA and theoretical T1 values are shown. Markers in orange color represent signal intensity between 200 and 680 [AU] which correspond to the signals of AP, PP, T, pons, and cord on T1-PETRA. The regression linear analysis showed high correlation $\left(\mathrm{R}^{2}=0.9862\right)$ between measured signal intensity on T1-PETRA and theoretical T1 values. Thus, signal intensity of measured our VOIs on T1-PETRA are considered to be parallel to T1 value. 


\section{Supplementary Material 7}

The posterior lobe of the pituitary gland (PP) is very small structure compared with the resolution of MRI, and 3D VOI of PP was chosen to a few voxels, therefore, we avoided the volume calculation for PP. On the other hand, we considered the signal intensity calculation of 3D VOI to be reliable because we found the high correlation of signal intensity of PP between 2D ROI created from the 3D VOI and the original 3D VOI $\left(\mathrm{R}^{2}=0.988\right)$.

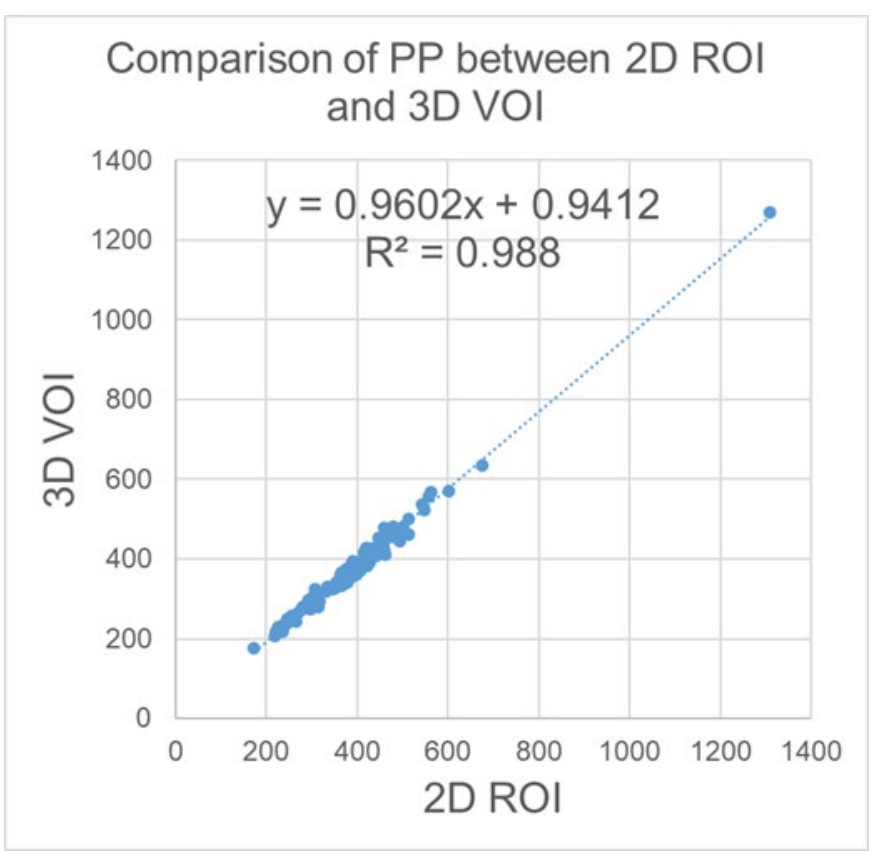




\section{Supplementary Material 8}

The equations of the regression lines used in Figure 3,4,5 and 6 are shown as below.

Figure 3. Scatter plots of GA, CA, GA+CA, BW and signal ratios of pituitary gland $\left(\mathrm{AP}_{\text {mean }} /\right.$ pons, $\mathrm{PP}_{\text {mean }} /$ pons) and thyroid gland ( $\mathrm{T}_{\text {mean }} /$ cord $)$.

$$
\begin{aligned}
& \mathrm{AP}_{\text {mean }} / \text { pons }=0.588966+0.0034395 \times \mathrm{GA} \\
& \mathrm{PP}_{\text {mean }} / \text { pons }=0.6563685+0.0050725 \times \mathrm{GA} \\
& \mathrm{T}_{\text {mean }} / \text { cord }=0.758997+0.0024562 \times \mathrm{GA} \\
& \mathrm{AP}_{\text {mean }} / \text { pons }=1.5991587-0.0043678 \times \mathrm{CA} \\
& \mathrm{PP}_{\text {mean }} / \text { pons }=2.1467469-0.0066009 \times \mathrm{CA} \\
& \mathrm{T}_{\text {mean }} / \text { cord }=1.4676774-0.0029196 \times \mathrm{CA} \\
& \mathrm{AP}_{\text {mean }} / \text { pons }=2.7629515-0.0048827 \times(\mathrm{GA}+\mathrm{CA}) \\
& \mathrm{PP}_{\text {mean }} / \text { pons }=3.6399187-0.0063876 \times(\mathrm{GA}+\mathrm{CA}) \\
& \mathrm{T}_{\text {mean }} / \text { cord }=2.151058-0.0029166 \times(\mathrm{GA}+\mathrm{CA}) \\
& \mathrm{AP}_{\text {mean }} / \text { pons }=1.1332142+0.0001413 \times \mathrm{BW} \\
& \mathrm{PP}_{\text {mean }} / \text { pons }=1.4831383+0.0001953 \times \mathrm{BW} \\
& \mathrm{T}_{\text {mean }} / \text { cord }=1.1440677+0.000101 \times \mathrm{BW}
\end{aligned}
$$

Figure 4. Scatter plots of GA, CA, GA+CA, BW and signal ratios of pituitary gland $\left(\mathrm{AP}_{\max } /\right.$ pons, $\mathrm{PP}_{\max } /$ pons) and thyroid gland $\left(\mathrm{T}_{\max } /\right.$ cord $)$.

$$
\begin{aligned}
& \mathrm{AP}_{\max } / \text { pons }=0.4317123+0.0053534 \times \mathrm{GA} \\
& \mathrm{PP}_{\max } / \text { pons }=0.3132611+0.0086233 \times \mathrm{GA} \\
& \mathrm{T}_{\max } / \text { cord }=0.5415191+0.0051134 \times \mathrm{GA} \\
& \mathrm{AP}_{\max } / \text { pons }=1.9838315-0.0063202 \times \mathrm{CA}
\end{aligned}
$$




$$
\begin{aligned}
& \mathrm{PP}_{\max } / \text { pons }=2.8278925-0.010843 \times \mathrm{CA} \\
& \mathrm{T}_{\max } / \text { cord }=2.0143122-0.0059674 \times \mathrm{CA} \\
& \mathrm{AP}_{\max } / \text { pons }=3.1598216-0.0052658 \times(\mathrm{GA}+\mathrm{CA}) \\
& \mathrm{PP}_{\max } / \text { pons }=5.0297778-0.0095906 \times(\mathrm{GA}+\mathrm{CA}) \\
& \mathrm{T}_{\max } / \text { cord }=3.213345-0.0052662 \times(\mathrm{GA}+\mathrm{CA}) \\
& \mathrm{AP}_{\max } / \text { pons }=1.3143833+0.0002018 \times \mathrm{BW} \\
& \mathrm{PP}_{\max } / \text { pons }=1.4831383+0.0001953 \times \mathrm{BW} \\
& \mathrm{T}_{\max } / \text { cord }=1.3457346+0.0002104 \times \mathrm{BW}
\end{aligned}
$$

Figure 5. Scatter plots of GA, CA, GA+CA, BW and volume of pituitary gland (AP_vol) and thyroid gland (T_vol).

$$
\begin{aligned}
& \text { AP_vol }=-44.59464+0.4465435 \times \mathrm{GA} \\
& \mathrm{T}_{-} \text {vol }=-195.9376+3.6497413 \times \mathrm{GA} \\
& \mathrm{AP}_{-} \text {vol }=79.650317-0.4224301 \times \mathrm{CA} \\
& \mathrm{T}_{-} \text {vol }=821.49605-3.5512543 \times \mathrm{CA} \\
& \mathrm{AP}_{-} \text {vol }=65.234878-0.0201368 \times(\mathrm{GA}+\mathrm{CA}) \\
& \text { T vol }=831.82723-0.6276834 \times(\mathrm{GA}+\mathrm{CA}) \\
& \text { AP_vol }=25.522053+0.0186052 \times \mathrm{BW} \\
& \mathrm{T}_{-} \text {vol }=343.29188+0.1691712 \times \mathrm{BW}
\end{aligned}
$$

Figure 6. Scatter plots of volume of pituitary gland (AP_vol) and thyroid gland (T_vol) and signal ratios of anterior pituitary gland ( $\mathrm{AP}_{\operatorname{mean}} /$ pons, $\mathrm{AP}_{\max } /$ pons) and thyroid gland ( $\mathrm{T}_{\text {mean }} /$ cord, $\mathrm{T}_{\max } /$ cord $)$.

$$
\mathrm{AP}_{\text {mean }} / \text { pons }=1.1422312+0.0041938 \times \mathrm{AP}_{-} \text {vol }
$$




$$
\begin{aligned}
& \mathrm{AP}_{\max } / \text { pons }=1.3313356+0.005923 \times \mathrm{AP}_{-} \mathrm{vol} \\
& \mathrm{T}_{\text {mean }} / \text { cord }=1.129946+0.0003063 \times \mathrm{T}_{-} \text {vol } \\
& \mathrm{T}_{\max } / \text { cord }=1.3651711+0.0005631 \times \mathrm{T}_{-} \text {vol }
\end{aligned}
$$

Scatter plots of signal ratio of anterior pituitary gland (AP $\mathrm{P}_{\text {mean }} /$ pons, $\mathrm{AP}_{\max } /$ pons $)$ and thyroid gland ( $\mathrm{T}_{\text {mean }} /$ cord, $\mathrm{T}_{\max } /$ cord).

$$
\begin{aligned}
& \mathrm{AP}_{\text {mean }} / \text { pons }=0.6996148+0.5224815 \times \mathrm{T}_{\text {mean }} / \text { cord } \\
& \mathrm{AP}_{\max } / \text { pons }=0.9044524+0.4520407 \times \mathrm{T}_{\max } / \text { cord }
\end{aligned}
$$

